\title{
Ref: JPMA_2018_179
}

\section{Author 1:}

Mehran Oraee

Email: mehran.oraee@unimelb.edu.au

Faculty of Architecture, Building and Planning

The University of Melbourne, Parkville, VIC 3010, Australia

Author 2 (corresponding author):

M. Reza Hosseini

Email: reza.hosseini@deakin.edu.au

School of Architecture and Built Environment

Deakin University, Geelong, Australia

\section{Author 3:}

David J Edwards

Email: drdavidedwards@,aol.com

Faculty of Technology Environment and Engineering

Birmingham City University

Visiting Professor Faculty of Engineering and the Built Environment University of Johannesburg, South Africa

\section{Author 4:}

Heng Li

Email: bshengli@polyu.edu.hk

Department of Building and Real Estate

Hong Kong Polytechnic University, Hong Kong

\section{Author 5:}

Eleni Papadonikolaki

Email: e.papadonikolaki@ucl.ac.uk

The Bartlett School of Construction \& Project Management

University College London, London, UK

\section{Author 6:}

Dongping Cao

Email: dongping.cao@tongji.edu.cn

School of Economics and Management

Tongji University, China 


\section{Collaboration Barriers in BIM-based Construction Networks: A Conceptual Model}

\section{ABSTRACT}

Building information modelling (BIM) teams, hereafter referred to as BIM-based construction networks, are teams whose possibly geographically dispersed members from various organisations and disciplines, perform project tasks on BIM-enabled projects. In recent years, BIM-based construction networks have progressively become the norm in executing BIM activities on projects. However, even though achieving BIM's full capabilities relies on effective collaboration among the team members in BIM-based construction networks, it is still a struggle for these members to collaborate. Nonetheless, only a few studies have been conducted to identify the barriers to strengthening team collaboration in BIM-based construction networks. To address this gap, the current study, by examining 73 journal articles on collaboration in BIM-based construction networks, builds upon a theoretical review of the literature. A conceptual model is presented to capture the main barriers to collaboration in BIM-based construction networks. The study benefits researchers as well as project managers. For researchers, the conceptual model provides an intermediate theory, namely, a theoretical basis to direct further knowledge creation attempts on the topic. In addition, the conceptual model supports project managers on BIM-enabled projects. That is, it simplifies the knowledge now available for practical applications enabling it to be translated into guidelines and practical instructions on real-life projects.

Keywords: BIM-enabled projects; collaboration; barriers; team development; virtual teams. 


\section{INTRODUCTION}

Building Information Modelling (BIM) is progressively permeating the construction industry, due to its potential capabilities in improving project practices in design, procurement, pre-fabrication, construction and postconstruction ( $\underline{\text { Cao et al., 2017a; }}$ He et al., 2017). Construction projects enabled by BIM are typically delivered through deploying BIM-based construction networks (BbCNs) (Mignone et al., 2016) in which teams comprising members from specialist organisations are contracted to execute BIM-related works (Grilo and Jardim-Goncalves, 2010; Grilo et al., 2013). The ability to enhance collaboration within these BbCNs is one of BIM's selling points (Cao et al., 2017a; Dossick and Neff, 2011). Moreover, collaboration in BbCNs is seen as a prerequisite for

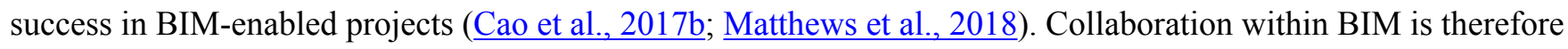
of paramount importance in construction project management.

Within the BbCNs setting, however, maintaining collaboration among members coming from multiple disciplines and organisations has proved problematic (Matthews et al., 2018). Evidence shows that members in BbCNs are still struggling to collaborate (Liu et al., 2017; Oraee et al., 2017b). This exposes BIM-enabled projects to a wide range of risks, among others, misunderstandings, misinterpretation of data and increased rework (Nikas et al., 2007). Poor collaboration continues to be one of the major risks affecting BIM-enabled projects (Zhao et al., 2017). Despite the significant effects of poor collaboration, a review of the literature on BbCNs collaboration reveals that serious gaps remain to be addressed, with little work focusing particularly on collaboration in BbCNs having been hitherto published (Oraee et al., 2017b; Santos et al., 2017; Zhang et al., 2017a). 
The lack of studies on barriers to collaboration in BbCNs is especially glaring. To be specific, barriers to BbCNs collaboration have only been partially mentioned in studies devoted to other features of BIM, such as contractual aspects, education, etc., a point argued by Mignone et al. (2016). Existing empirical studies devoted to barriers to collaboration, such as the work of Papadonikolaki et al. (2016), predominantly delve into case-based and contextual barriers to collaboration, or focus entirely on technological issues (Zhang et al., 2017b; Zhao et al., 2017). As a result, systematic studies continue to be needed that focus on meta-analysis to identify the barriers to collaboration in BbCNs, particularly from a sociotechnical perspective (Liu et al., 2017; Oraee et al., 2017b;

\section{Sackey et al., 2015).}

The current study addresses this need by performing a systematic literature review and bringing together the existing available literature on barriers to collaboration in BbCNs in the form of one integrated conceptual model. The study attempts to: (1) map the relevant intellectual territory available on barriers to collaboration in BbCNs, and (2) further develop the knowledge base through encapsulating the essence of the existing knowledge on the topic into one conceptual model. The proposed conceptual model contributes to further scholarship and to enhancing practice. For researchers, a sound foundation is provided as a stepping-stone and a theoretical basis to inform future empirical studies. As for project management practitioners, the proposed conceptual model provides a workable source for identifying barriers in real-life projects. This can be translated into useful guidelines based on the best available evidence to tackle major collaboration issues in BbCNs on real-life BIM-enabled projects. 


\section{THEORETICAL BACKGROUND}

\subsection{Collaboration in project teams}

Collaboration is indispensable in the successful execution and delivery of any type of project. From a project management perspective (PMI, 2017), collaboration relates to a wide range of project management knowledge areas: integration, communication, and resource and stakeholder management. Encouraging collaboration and a collaborative team culture are also among the primary responsibilities of project managers in developing effective teams, a point emphasised by PMI (2017). According to Walker et al. (2017), collaboration reduces ambiguity in projects and helps in identifying risks and uncertainties. Collaboration is also closely related to project team performance, and it is therefore essential for project managers to understand what factors affect their team members' collaboration (Caniëls et al., 2019).

Gray (1985) conceptualised collaboration as a procedure through which parties who face various aspects of a problem constructively explore their differences and find remedial solutions that extend beyond each party's limited vision of what might be possible. With this in mind, Ey et al. (2014) referred to collaboration on construction projects as the tendency to “...'shar[e] resources' including human, information, technology and knowledge for the greater good of the constituents of the partnership". Collaboration refers to an agreement among several specialists to share their capabilities, including available data, information and knowledge, in completing particular tasks, with the aim of achieving the project's broader objectives, as defined by their client, or stakeholders ( $\underline{\text { Hu et al., 2016; }}$ Hughes et al., 2012; Matthews et al., 2018). 


\subsection{Collaboration and BIM-enabled projects}

Construction is a highly project-based industry (Gann and Salter, 2000; Morris, 2004) in which various

organisations must couple with each other through project-specific collaborative relationships (Cao et al., 2018).

Construction activities are therefore inherently contingent upon collaboration among team members (Greenwood

and $\mathrm{Wu}, 2012$; Papadonikolaki et al., 2016). Conversely, the lack of collaboration in construction project teams

results in misunderstandings, misinterpretations of data, poor communication and, consequently, increased rework

(Greenwood and Wu, 2012; Hosseini et al., 2017; Kalay, 2001; Nikas et al., 2007). Thereby, collaboration is seen

as "the mainstay" for improving efficiency, integrating processes and resources, increasing profit and enhancing

the quality of products on construction projects (Ey et al., 2014; Fulford and Standing, 2014; Greenwood and Wu,

2012; Kalay, 2001).

With BIM's advent, its technical capabilities in facilitating a collaborative environment have been a major

motivator for construction projects in their move towards BIM's implementation (Alreshidi et al., 2016a;

Bassanino et al., 2014; Cao et al., 2016; Hosseini et al., 2016). Indeed, BIM is promoted as the ultimate solution

for collaboration problems across the construction supply chain (Howard et al., 2017). However, contrary to this

commonly held assumption, evidence shows that BIM-enabled projects are facing endemic problems in terms of

collaboration among team members (Cao et al., 2015; Manderson et al., 2017; Mignone et al., 2016;

Papadonikolaki et al., 2016; Zhang et al., 2017b).

In theory, BIM has great potential for enhancing collaboration (Ashcraft, 2008; Dossick and Neff, 2011).

However, a lack of understanding is still evident where BIM is introduced about what enablers and organisational 
forces need to be in place for collaboration to occur (Dossick and Neff, 2010; Matthews et al., 2018; $\underline{\text { Sackey et al., }}$

2015; Zhang et al., 2017b). This problem is acknowledged by industry publications which report that, despite

BIM's inherently collaboration-oriented nature, the benefits of collaboration are being realised only in a relatively

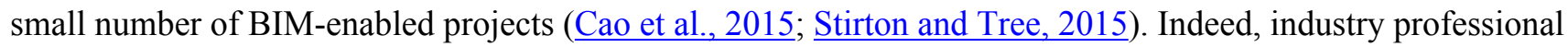

bodies allocate significant amounts of resources to enhancing collaboration among parties involved in BIM-

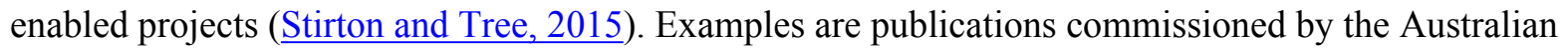

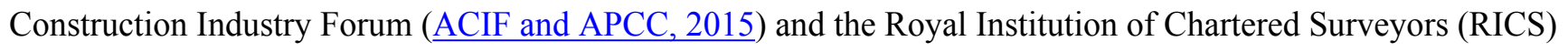

(Baddeley and Chang, 2015) and the best practices of case projects and organisations (

\subsection{BIM-based construction networks (BbCNs)}

Building Information Modelling (BIM)-based construction networks (BbCNs) have become the typical working unit for implementing BIM in construction projects (Mignone et al., 2016; Oraee et al., 2017b). These teams typically comprise members from various disciplines and organisations, each possessing particular skill sets to fulfil BIM-related project requirements (Grilo et al., 2013; Hosseini et al., 2017). Given the nature of BbCNs' structure, their goal achievement and success rely upon team members working collaboratively, openly sharing project data and information across all disciplines and organisations involved (Hosseini et al., 2016; Merschbrock, 2012; Stirton and Tree, 2015; Zhang et al., 2017b). Therefore, BIM implementation, in the absence of collaboration in such teams, is described as "scratching the surface." (Ashcraft, 2008; $\underline{\text { Shen et al., 2010) }}$ Consensus is acknowledged in the field on the crucial role of collaboration in BbCNs (Alreshidi et al., 2016a;

Grilo and Jardim-Goncalves, 2010; Merschbrock, 2012; Mignone et al., 2016; Zhang et al., 2017b). 
Collaboration in BbCNs is, however, a multifaceted complex phenomenon, affected by a variety of factors (Liu et al., 2017; Shen et al., 2010; Zhang et al., 2017a). Included are technological factors such as interoperability (Yalcinkaya and Singh, 2015; Zhao et al., 2017), as well as the social features of teamwork including culture, and contractual and organisational aspects (Manderson et al., 2017; Turk, 2016). The literature also highlights the central role of personnel who possess collaboration skills (He et al., 2017; Liu et al., 2017; Merschbrock, 2012;

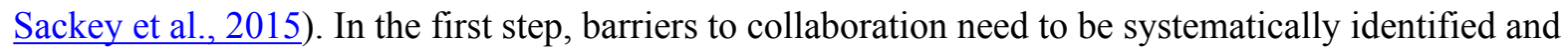
subsequently addressed (Alreshidi et al., 2016a; Merschbrock, 2012; Mignone et al., 2016; Poirier et al., 2016).

\subsection{Relevant work and research gap}

As discussed, a major part of the research associated with barriers to collaboration in BbCNs comes from studies which, although devoted to other areas of BIM, also partially touch on these barriers (Merschbrock et al., 2018;

Oraee et al., 2017b). These barriers are discussed below, organised around the themes of procurement, accountability, skills, technology and behaviour.

Eastman et al. (2008) and Turk (2016) claimed that procurement is highly formative of BIM success in projects and that, within procurement, integrated forms are a better fit. In any project, BIM is affected by two contexts: its immediate project context and the external societal and industrial context (Turk, 2016). In targeting contractual aspects, the wide range of barriers to collaboration in $\mathrm{BbCNs}$ is attributed to the traditional legal structure enforced in construction projects (cf.Alwash et al., 2017; Ashcraft, 2008; Cao et al., 2015; Kuiper and Holzer, 2013; Olatunji, 2011b). The premise promoted here, and acknowledged by industry observations, denotes that many of the now-available contracts used on construction projects were drafted in pre-BIM days (Manderson et 
al., 2015; Manderson et al., 2017). Furthermore, using these contracting models on BIM-enabled projects hampers the development of collaboration (Ashcraft, 2008; Stirton and Tree, 2015). Changes to contracts are required to allow successful and collaborative implementation of BIM within the network of organisations responsible for the delivery of BIM-enabled projects (Taylor, 2007). Using a relationship contracting model, such as integrated project delivery (IPD), has been suggested as the necessary underlying contractual framework to foster collaboration among project participants (Bryde et al., 2013; Tingting et al., 2017).

With transparency of information a significant aspect of BIM systems, major barriers are the inability to reach agreement on the ownership of the BIM model (BIM) and the lack of agreement on who is to allocate resources to maintain it over the entire building life cycle (Kalantari et al., 2017; Rezgui et al., 2013). Much debate also continues on the insurance of the design liability and the ramifications of identified clashes for the associated parties (Brodie, 2010; Manderson et al., 2015). In a recent attempt, Zhang et al. (2017a) argued that major barriers to collaboration revolve around practitioners' behaviour towards data ownership rather than technology.

Studies by Becerik-Gerber et al. (2012) and later by Zhao et al. (2015), along with an industry case study by Matthews et al. (2018), established that today's BIM practitioners do not possess the skills and abilities to collaborate as team members on BIM-enabled projects. This assumption has triggered the delivery of several studies focused on BIM's education and learning aspects, as an avenue towards enhancing collaboration in BIMenabled projects (Arayici et al., 2011; Pikas et al., 2013a; Sacks and Pikas, 2013). As a result, the integration of interdisciplinary collaboration into the curricula of construction-related courses has become part of the agenda for preparing students with adequate skills to work on BIM-enabled projects (Abdirad and Dossick, 2016; Hosseini et 
al., 2018; Wu and Issa, 2013; Zhang et al., 2018). Research has been conducted on outlining BIM's industry requirements, yet translating these requirements into curricula and education programs remains in its infancy (ACIF and APCC, 2017; Hosseini et al., 2018).

Collaboration on construction projects requires the use of standards that determine the rules of engagement among the parties involved in delivering the projects (Bouchlaghem et al., 2005). A process is standardised provided it is executed each time in a predefined way with the same activities performed in the same sequence to produce exactly the same output (ooper, 2015). With this in mind, the literature on BIM suffers from a general lack of attention to the standardisation of BIM (Santos et al., 2017), presenting a serious barrier to collaboration in BbCNs, as argued by Merschbrock and Munkvold (2014). Industry publications, such as the work of Beesley (2013), and researchers, like Turk (2016), have also highlighted the importance of BIM standardisation in enhancing collaboration and fostering interoperability. Standardisation of BIM facilitates the smoothening of model sharing and easy exchange of data between multiple stakeholders, contractors and end-users on BIMenabled projects (Beesley, 2013; Hooper, 2015).

From a technology "push" perspective, the existing immature technology has been regarded as a formidable barrier to collaboration in a wide range of studies (Merschbrock, 2012; Zhang et al., 2017a; Zhang et al., 2017b). Technology "push" has become a significant theme, with the primary topics of interest being constant development of the technical requirements of collaboration, and the impacts of virtual working, interoperability, data exchange and industry foundation classes (IFC) (Shafiq et al., 2013; Yalcinkaya and Singh, 2015). Another stream of research in recent years (Comiskey et al., 2017) is exploration of various platforms to facilitate 
information exchange among BIM users in a common data environment (CDE). Similarly, attention is being increasingly attracted to defining effective collaboration models and arrangements (Manderson et al., 2017;

Zhang and Ashuri, 2018). Despite the popularity of the theme of technology "push", technology cannot be seen as the only barrier (Sackey et al., 2015). The problem of collaboration in BbCNs has its roots in human behaviour (Emmitt and Ruikar, 2013; Grilo and Jardim-Goncalves, 2010; Liu et al., 2017; Sackey et al., 2015).

The review of the existing literature has shown that the problem highlighted in the above points has been approached in isolated, fragmented and disjointed attempts which have disregarded the interrelationships and mutual interdependencies among the influential factors (Sackey et al., 2015). Simultaneously, all aforementioned otherwise excellent studies rely on empirical data mainly from case studies with limited generalisation potential. An integrated meta-analysis of these studies and the collaboration barriers that they propose can shed more light on the barriers to collaboration when working with BIM-enabled projects. Hence, an integrated approach towards

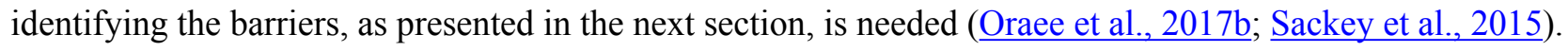

\section{THEORETICAL LENS}

An effective approach towards the extraction of the meaning and tenet of qualitative data, including texts from published studies, is to focus on comparison, contrast and similarity against an established theoretical base (Bazeley, 2013). In essence, using a theoretical lens enhances the generalisability of findings in bottom-up studies that build on the now available knowledge to create new knowledge (Lewins and Silver, 2007). The current study, taking this into consideration, therefore selected a theoretical lens. 
"There is neither a unified nor distinct theory of collaboration" Williams (2016). Theoretical lenses, hitherto used to inform the existing studies on collaboration, are thematically defined frameworks for prioritising key variables (D'Amour et al., 2005; Williams, 2016). Moreover, collaboration is highly context-specific, affected by the following aspects of the collaboration unit: its nature and organisational structures, participants' attributes, the scale of potential conflicts and the unit's size (D'Amour et al., 2005; Williams, 2016). This necessitated the use of a theoretical lens developed for, and applicable to, the BbCNs context.

The Co-Spaces Collaborative Working Model (CCWM), proposed by Patel et al. (2012), is the outcome of a comprehensive review of the literature that categorised the factors influencing collaboration in engineering workspaces, including in architectural and construction activities. Later, Poirier et al. (2016) synthesised the findings of the available noteworthy studies on factors affecting collaboration and, for technological innovations, such as BIM, encapsulated them in the form of a framework. More recently, Oraee et al. (2017b) combined the two aforementioned frameworks into a conceptual model, an adapted version of which is illustrated in Figure 1. This typology is the most recent provided for the factors that affect collaboration in BbCNs, being both reflective of the outcomes of two major studies on the topic and informed by a multidisciplinary approach to collaboration. In addition, the model captured the interrelated impacts of factors that affect collaboration in BbCNs (Sackey et al., 2015), and was developed for the BbCNs context. With these facts in mind, the model, being deemed suitable, was selected as the current study's theoretical lens.

$<<$ INSERT FIGURE 1 HERE $>>$

Figure 1. Theoretical lens of the study (adapted from Oraee et al. (2017b)) 
The study's theoretical lens, illustrated in Figure 1, denotes that all factors that affect collaboration in BbCNs, although interrelated, come under the following five categories: context, process, team, task and actor (cf.Oraee et al., 2017b; Patel et al., 2012). 'Process' covers essential tools, necessary resources and professional training for collaboration. In this definition, the term 'tools' refers to the relevant software and technologies and their compatibility, capabilities and specifications to communicate and collaborate in BIM-enabled projects. Project members and teams also need appropriate resources, such as physical space and equipment, in order to collaborate and perform their tasks. Moreover, professional training is required on the use of collaboration tools and on the act of collaboration in BIM projects to complete the tasks.

The term 'tasks' refers to the characteristics of BIM tasks including task demand, which depends on work situations, and task structure, which is appropriate to task demand and may be affected by its complexity. 'Teams' represent the relationship system of BbCNs,and the understanding of team members of their colleagues' roles within the team to establish shared knowledge. Furthermore, the term 'teams' is concerned with team composition: team members may differ in age, culture, gender, education, experience, roles and attitudes. The term 'actors' refers to the skills and performance of members in BbCNs in terms of their social and professional activities. In fact, actors in BbCNs bring their own set of skills, knowledge and abilities to collaboration. The 'context' factor reflects the specific environment within which all these identified antecedents are set. As discussed, in line with the current study's objective of integrating the available findings into one conceptual model, the selected theoretical lens served as the comparative context for the interpretation of data for analysis 
purposes, and for organising a framework to represent the data after analysis. The theoretical lens entered the project at the inception of data analysis, as described in the next section.

\section{METHODOLOGY AND RESEARCH METHODS}

The literature review, as a research methodology, was grounded in a constructivist philosophical frame. The reason is that the review of the relevant literature identified the multiple perspectives of BbCNs collaboration barriers, with these multiple realities recognised as co-existing in the minds of researchers and scholars investigating the phenomenon (Crotty, 1998). Therefore, throughout the current study, more emphasis was given to qualitative than to quantitative analyses (Greene, 2008). To this end, the study followed an inductive reasoning approach as the researchers moved from the data to the formulation of theory in a longitudinal time horizon.

The study's defined objective was pursued through explanation building, by conducting a theoretical review, in accordance with the typology of review studies proposed by Paré et al. (2015). This theoretical review aimed to make a contribution to the world of practice while providing a conceptual framework to guide future research efforts. The principal aim of the theoretical review was construed to be in line with the current study's objective for the reason that it " draws on existing conceptual and empirical studies to provide a context for identifying, describing, and transforming into a higher order of theoretical structure and various concepts, constructs or relationships." (Paré et al., 2015) Furthermore, as discussed, investigating the barriers to collaboration in BbCNs has remained an under-researched area. Theoretical reviews add great value to the body of knowledge of such underdeveloped topics by conceptualising and synthesising the existing information into conceptual frameworks that act as intermediate theories (Shields and Tajalli, 2006). 
As illustrated in Figure 2, conducting the review entailed three major activities: (1) emulating the approach taken by von Danwitz (2018); (2) scoping and collecting and; (3) reducing and, eventually, analysing the list of identified studies, with a description of each of these activities provided below.

\section{$<<$ INSERT FIGURE 2 HERE $>>$}

Figure 2. Research design (adapted from Oraee et al. (2017b))

\subsection{Scoping and collecting}

The activity of scoping focused on identifying the key contributors to the existing body of knowledge on the topic, while the collecting phase involved gathering the related data and information from these identified sources (von Danwitz, 2018). The predefined list of searched for and identified items provides a reproducible source for review studies (von Danwitz, 2018). With this in mind, as illustrated in Figure 2, 62 journal articles were identified by Oraee et al. (2017b) as the most relevant studies available on BbCNs collaboration. This formed a preliminary list of available studies. It needs to be noted that this study covered only published journal articles, in line with the approach taken by Oraee et al. (2017b). To incorporate the most recent journal articles, the exact search terms, namely, the keywords used by Oraee et al. (2017b), including "Building Information Modelling", "BIM", "collaboration" and "collaborative", were applied on Scopus to search for relevant articles on the topic. The list of all keywords and the exact search terms on Scopus are presented in the Appendix. The Scopus platform, as utilised by Oraee et al. (2017b), was selected to ensure that the sample was comprehensive, covering the most recent published articles, and also to provide a reproducible process. This process identified 101 recently published journal articles (as of 10 January 2018). The new search to identify the most recent studies on the topic 
was limited to studies published in 2017 and 2018, which resulted in the identification of 98 studies in 2017 and

three (3) studies in 2018. A brief analysis of the latter three studies indicated that the actual research for these

publications was based in 2017; however, the date of their publication was set for early 2018. Consequently, they were regarded as research studies completed in 2017. The data set in this study therefore covered 163 published journal articles, comprising 101 studies published in 2017 and early 2018, and 62 relevant studies, identified by Oraee et al. (2017b), that covered research between 2006 and early 2018. It is noteworthy that the first use of the

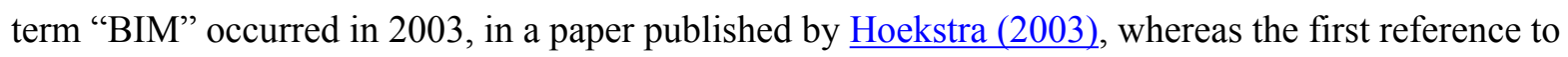

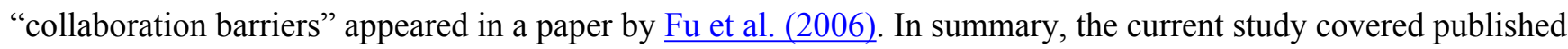
journal articles published between 2006 and 2018 that discussed BbCNs collaboration.

\subsection{Reducing (inclusion/exclusion protocols)}

The activity of reducing was conducted to retain those studies that met all the inclusion criteria and manifested none of the exclusion criteria, according to the predefined protocol, to ensure only the most appropriate publications were analysed (Tranfield et al., 2003). Drawing from the lessons in the work by Tranfield et al. (2003), the current study adopted the following protocol:

- The research selected was designed and conducted within the BIM context, and

- The research selected elaborated at least one specific experience or intervention pertaining to the challenges of $\mathrm{BbCNs}$ collaboration.

In the current study, all 163 identified journal articles were reviewed by all research team members, with each article discussed one by one in online meetings. One article was omitted when no team member could supply a reason for its retention. As shown in Figure 2, this process resulted in the retention of 73 journal articles, 
including 56 from the list by Oraee et al. (2017b) and 17 from the most recent studies published in 2017 and early 2018, with all articles discussing challenges and barriers to collaboration in BbCNs, in particular.

\subsection{Analysis (coding)}

According to Miles and Huberman (1994), the systematic analysis of qualitative data is typically performed through coding. This effective approach towards extracting meaning from any type of qualitative data, including published studies, leads to deeper insight and makes marking and sorting of qualitative data doable at greater speed, with more flexibility and accuracy (Bazeley, 2013). In the current study, analysis of the content of studies entailed a two-stage procedure. In the first stage, relevant statements about barriers to collaboration were detected within the corpus of passages in the identified studies. The research team identified these passages by selecting empirical claims - in the form of codes - about barriers to collaboration in the selected studies. These codes were copied word-for-word into a spreadsheet, following the prescriptions of Saldanā (2009) on in vivo coding.

The second stage involved assigning meanings to statements in the spreadsheet by categorising them, namely, coding each statement using descriptive codes ( $\underline{\text { Saldanā, 2009)}}$. In accordance with the approach recommended by Bazeley (2013), the first stage of coding in the current study was conducted through analysing the articles and interpreting the identified barriers against a list of a priori concepts (codes) to ensure interpretive convergence. The list of a priori codes in this study comprised the five main categories and their sub-categories as set out by the study's theoretical lens (see Figure 1).

The principal focus area of the study described in each article was assigned a code (or more than one code) when all research team members had agreed upon the selected code or codes, with coding discussed in regular online 
meetings. In cases of disagreement, discussions continued until agreement was reached. The outcome of the coding process was the allocation of 89 barriers to the five major categories as set out by the study's theoretical lens, comprising context, process, team, task and actor. In the coding's second stage, the coded barriers to each major category were analysed by the research team so that barriers describing a similar concept could be merged.

As a result, the above list was reduced to 26 barriers.

In the final stage of coding, the identified 26 barriers were coded against the identified sub-categories as set out by the study's theoretical lens (see Figure 1). As in the first stage of coding, each barrier was assigned a code (sub-category) when all research team members agreed upon the selected code, with coding discussed in regular online meetings.

\section{FROM CODING TO FINDINGS}

\subsection{Barriers as reflected in the literature}

The full texts of all 73 journal articles were coded, with the identified 89 barriers allocated to the major five categories and, subsequently, to their sub-categories, as per the study's theoretical lens. In coding qualitative data, including published studies, the frequency associated with a code is regarded as its relative importance in the data set: important items are those that are repeated more frequently (Bazeley, 2013). Thus, the importance and increasing focus on barriers to collaboration in $\mathrm{BbCNs}$, as reflected in the now available literature, is shown in Figure 3. 
As inferred from Figure 3, since 2006, awareness of barriers to collaboration in BbCNs has been growing in the literature, with a noticeable upsurge in 2017. As reflected in Figure 3, the first burst of research on teamwork and collaborative design concluded in 2015, as indicated by the burst analysis conducted by He et al. (2017). In 2016 and 2017, studies indicated an increasing awareness of various dimensions of barriers, hinting at a raised understanding of the interrelationships and synergistic impacts of barriers on BbCNs collaboration.

Notwithstanding this, studies on barriers to collaboration in $\mathrm{BbCNs}$ for the most part (see Figure 3) have focused on 'process' barriers. The next most explored barriers are those under 'context' and 'actor'. Studies on barriers to BbCNs collaboration focus least on 'team' and 'task'. This observation of the dominance of 'process' barriers (shorthand for technical barriers) is in line with previous studies' arguments on collaboration in BbCNs, asserting that technology "push" has remained the prevalent theme of the available studies (cf.Liu et al., 2017; Mignone et al., 2016; Oraee et al., 2017a).

\subsection{Constructs of the model}

The first step towards developing a conceptual model involves identifying the constructs to be included, namely, identifying the factors that logically explain part of the phenomenon of interest (Whetten, 1989). In the current study, these constructs were the barriers identified in the process of coding through the study's theoretical lens, as discussed below.

\subsubsection{Process barriers}

As shown in Table 1, the largest group of process barriers were those associated with tools, followed by barriers stemming from information and communications technology (ICT). Very few process barriers were allocated to training. 
Table 1. Process-related barriers to collaboration in BbCNs

\begin{tabular}{|c|c|c|}
\hline Factor & Barrier & Description \\
\hline \multirow{3}{*}{ Tools } & Failures in technological support & $\begin{array}{l}\text { BIM and collaboration tools do not perform as } \\
\text { advertised be vendors }\end{array}$ \\
\hline & Interoperability challenges across project life cycle & $\begin{array}{l}\text { Some tools common in the industry are not } \\
\text { compatible with the BIM open formats like IFC and } \\
B C F\end{array}$ \\
\hline & Complexities of adopting collaboration tools & $\begin{array}{l}\text { Due to the high number of available BIM tools, } \\
\text { companies need to spend much time in cherry- } \\
\text { picking the right tool/s for their projects }\end{array}$ \\
\hline \multirow{3}{*}{ Resources } & Lack of guidelines and standards on collaboration & $\begin{array}{l}\text { Lack of clear guidelines and standards to inform } \\
\text { collaboration processes in BIM }\end{array}$ \\
\hline & Data ownership and data privacy concerns & $\begin{array}{l}\text { Companies have concerns regarding the privacy } \\
\text { and security of BIM models to be shared on cloud } \\
\text { platforms and CDE }\end{array}$ \\
\hline & Lack of a common data environment (CDE) & $\begin{array}{l}\text { The number of available CDE platforms in the } \\
\text { industry remains limited }\end{array}$ \\
\hline Training & Inefficient BIM education on collaboration & $\begin{array}{l}\text { BIM and collaboration education is not adequate, } \\
\text { resulting in graduates with insufficient knowledge } \\
\text { on these topics }\end{array}$ \\
\hline
\end{tabular}

Sources: (Abrishami et al., 2014; Akponeware and Adamu, 2017; Alreshidi et al., 2016b, 2017; Amann and Borrmann, 2016; Arayici et al., 2018; Bassanino et al., 2014; Beach et al., 2017; Becerik-Gerber et al., 2011; Boton et al., 2013; Bozoglu, 2016; Cao et al., 2017b; Chen and Hou, 2014; Chen et al., 2013; Ciribini et al., 2016; Comiskey et al., 2017; Du et al., 2017; Fernando et al., 2013; Fu et al., 2006; Goulding et al., 2014; Grilo and Jardim-Goncalves, 2013; Hassan Ibrahim, 2013; Hosseini et al., 2018; Hu et al., 2016; Hu and Zhang, 2011; Isikdag, 2012; Isikdag and Underwood, 2010; Jiao et al., 2013; Kim et al., 2017; Lee et al., 2015; Liu et al., 2015; Ma and Ma, 2017; Niknam and Karshenas, 2015; Rafiq and Rustell, 2013; Shafiq et al., 2013; Shin, 2017; Sidawi and Hamza, 2012; Singh et al., 2011; Solnosky, 2016; Wei et al., 2014; Zhang et al., 2017a)

As shown in Table 1, the challenges of interoperability and exchange of information through BIM tools and software across the project phases and life cycle are regarded as major hindrances to BbCNs collaboration. This observation finds support in arguments by $\underline{\mathrm{Hu} \text { et al. (2016) }}$ and Lee et al. (2015), both of whom argued that information exchange in IFC formats is problematic, the reason being that existing collaboration tools have inadequate interoperability in different project phases. Moreover, Sidawi and Hamza (2012) identified that, 
although many generic collaboration tools are available, collaboration in each BIM-enabled project needs a customised tool to address the unique challenges to that project. From the practice world, construction practitioners have argued that they are not confident in IFC data exchange: in addition, graphical user interfaces (GUIs) of existing collaboration tools require significant improvement (Charalambous et al., 2017). Despite recent advancements, inefficient ICT-based solutions, such as cloud-based collaboration and data management platforms, are still not sufficiently effective in providing technical features to support information sharing, process management, exploration space, privacy and flexible system configuration (Du et al., 2017; $\underline{\text { Ma and Ma, }}$ 2017). Moreover, Beach et al. (2017) and industry standards like PAS 1192-5 (CPNI, 2015) have voiced concerns over the security of data, data ownership and data storage, all of which are barriers to BbCNs collaboration.

\subsubsection{Context barriers}

The context barriers, shown in Table 2, are categorised based on three different sub-factors of collaboration in

BbCNs: environment, organisational and culture.

Table 2. Context-related barriers to collaboration in $\mathrm{BbCNs}$

\begin{tabular}{lll}
\hline Factor & Barrier & Description \\
\hline \multirow{2}{*}{ Environment } & $\begin{array}{l}\text { Dynamics and fragmented nature of the } \\
\text { construction industry }\end{array}$ & $\begin{array}{l}\text { The construction industry including companies and } \\
\text { supply chain components are generally dispersed in } \\
\text { different locations, cities, and countries }\end{array}$ \\
\hline \multirow{3}{*}{ Organisation } & Lack of contractual standards around BIM models & $\begin{array}{l}\text { Lack of clear standards and BIM-friendly contracts } \\
\text { on the level of developments and requirements of } \\
\text { BIM-enabled projects }\end{array}$ \\
\cline { 2 - 3 } & Different organisational structures in & $\begin{array}{l}\text { Team members in BIM-enabled projects come from } \\
\text { various organisation, with different organisational } \\
\text { structures and hierarchies }\end{array}$ \\
\cline { 2 - 3 } Culture & Dultidisciplinary teams & $\begin{array}{l}\text { Each team member has a different understanding of } \\
\text { BIM collaboration requirements }\end{array}$ \\
\cline { 2 - 3 } & concept across the industry & $\begin{array}{l}\text { Assuming the same level of understanding of BIM } \\
\text { collaboration in project teams, the ways they } \\
\text { collaborate are different from others }\end{array}$ \\
\cline { 2 - 3 } & organisations &
\end{tabular}


Overlooking of national cultural variations in multicultural teams

Fragmented stakeholders as the norm

Lack of teamwork mentality
Members of project teams may have different national culture affecting the way they collaborate in BIM projects

In BIM-enabled projects, teams and their members are usually dispersed across various offices and locations

Members of the teams in BIM projects mainly tend to work in silos

Integration of people, process and technologies in BIM projects is not given the priority it deserves

While teams are working in BIM-enabled projects and in BIM environment, still many communications happen outside the BIM platform, e.g. phone calls and emails etc.

Sources: (Abuelmaatti and Ahmed, 2014; Dossick and Neff, 2009; Franz et al., 2016; Isikdag and Underwood, 2010; Jiao et al., 2013; Ku and Pollalis, 2009; Ma et al., 2018b; Merschbrock, 2012; Olatunji, 2011a; Papadonikolaki et al., 2016) (El-Diraby et al., 2017; Gu and London, 2010; Ku K et al., 2008; Liu et al., 2017; London and Singh, 2012; Ma et al., 2018b; Ochieng and Price, 2010; Oraee et al., 2017b; Owen et al., 2010; Poirier et al., 2016; Sackey et al., 2015; Van Gassel et al., 2014; Wallace Imoudu et al., 2014)

As shown in Table 2, content analysis of the studies regarding context barriers highlighted that the most important context-based barriers to BbCNs collaboration were associated with organisations. According to the findings, the most influential organisational barriers included the lack of contractual standards on BIM models $(\underline{\mathrm{Ku}}$ and

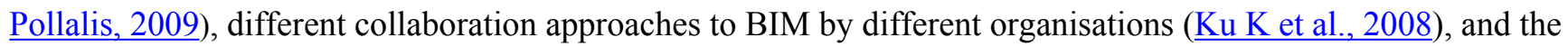
lack of appropriate inter-organisational BIM processes (Merschbrock, 2012). This was also the case for different organisational structures (matrix, divisional, functional and network) in multidisciplinary collaboration (Olatunji, 2011a), with the spatial layout of BbCNs (co-located vs. dispersed) (Mignone et al., 2016) being among the major context barriers to BcBN collaboration.

In addition to organisational barriers, cultural barriers were significant in BbCNs collaboration. That is, Ma et al.

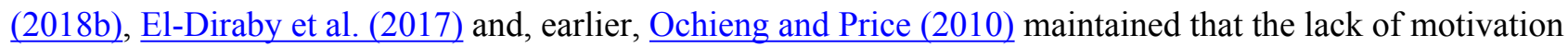


among stakeholders for their integration at the early stage and various communication attitudes between project

participants can lead to ineffective collaboration.

\subsubsection{Actor barriers}

Actor barriers, as shown in Table 3, were almost entirely concerned with areas associated with members'

knowledge, skills and abilities (KSAs).

Table 3. Actor-related barriers to collaboration in $\mathrm{BbCNs}$

\begin{tabular}{lll}
\hline Factor & Barrier & Description \\
\hline Skills & Insufficient collaboration knowledge, skills & $\begin{array}{l}\text { Members involved in teams in BbCNs have limited } \\
\text { knowledge of BIM concept, insufficient skills in BIM } \\
\text { tools, and insufficient understanding of BIM process } \\
\text { and relevant collaborative requirements }\end{array}$ \\
\hline
\end{tabular}

Sources: (Badi and Diamantidou, 2017; Comiskey et al., 2017; Gu and London, 2010; Hosseini et al., 2018; Kent and Becerik-Gerber, 2010; Kihong Ku and Mahabaleshwarkar, 2011; Kokkonen and Alin, 2016; Liu and Gao, 2017; Matthews et al., 2018; Olatunji, 2011a; Pikas et al., 2013b; Sackey et al., 2015; Solnosky et al., 2014; $\underline{\text { Succar, 2009) }}$

In this regard, studies by Kokkonen and Alin (2016), Solnosky et al. (2014) and Pikas et al. (2013b) indicated that even those organisations currently implementing BIM still struggle with training and access to employees who possess the skills to use BIM to manage and collaborate. In other words, lack of necessary skills, particularly interdisciplinary communications and collaboration competencies have not been improved to match BIM developments (okkonen and Alin, 2016). With this in mind, Becerik-Gerber et al. (2011), Abdirad and Dossick (2016) and Zhang et al. (2018) from academia, alongside ACIF and APCC (2017) from industry, have called for the inclusion of educational and training programs on collaboration within the tertiary education curricula.

\subsubsection{Team barriers}


Team barriers are challenges to collaboration in the form of the composition of BbCNs, relationships among members in $\mathrm{BbCNs}$, and knowledge sharing inter- and intra-BbCNs. These barriers were identified from the literature and are tabulated in Table 4Error! Reference source not found..

Table 4. Team-related barriers to collaboration in $\mathrm{BbCNs}$

\begin{tabular}{|c|c|c|}
\hline Factor & Barrier & Description \\
\hline Composition & Unsupportive team configuration and structure & $\begin{array}{l}\text { Teams' composition are mainly structured in } \\
\text { traditional forms that do support BIM } \\
\text { tasks/environment }\end{array}$ \\
\hline \multirow{3}{*}{ Relationships } & The isolated working mentality of project teams & $\begin{array}{l}\text { Teams involved in BIM projects mainly tend to work } \\
\text { in silos and look after their own interests }\end{array}$ \\
\hline & Resistance towards sharing data and information & $\begin{array}{l}\text { Teams in BIM projects are not willing to share their } \\
\text { models with other teams due to intellectual property } \\
\text { and ownership concerns }\end{array}$ \\
\hline & $\begin{array}{l}\text { Unestablished working collaboration between } \\
\text { designers and downstream supply chain }\end{array}$ & $\begin{array}{l}\text { Designers in BIM projects avoid sharing their } \\
\text { models with other stakeholders before completion of } \\
\text { the model and obtaining approvals }\end{array}$ \\
\hline \multirow[b]{2}{*}{ Roles } & $\begin{array}{l}\text { New roles (BIM manager and BIM coordinator) } \\
\text { are not adequately established }\end{array}$ & $\begin{array}{l}\text { In many BIM-enabled projects, traditional project } \\
\text { managers are still managing the whole BIM process, } \\
\text { in lieu of BIM managers/coordinators }\end{array}$ \\
\hline & $\begin{array}{l}\text { Competition between PM, IT manager and BIM } \\
\text { manager in managing teams }\end{array}$ & $\begin{array}{l}\text { Due to the nature of a BIM-enabled project, heavily } \\
\text { relied on software and tools, conflicts happen } \\
\text { between traditional project managers, IT managers } \\
\text { and BIM managers }\end{array}$ \\
\hline
\end{tabular}

Sources: (Mignone et al., 2016) (Akponeware and Adamu, 2017; Goulding et al., 2014; Isikdag and Underwood, 2010; Liao et al., 2017; London and Singh, 2012; Poirier et al., 2017) (Badi and Diamantidou, 2017; Dossick and Neff, 2009)

Among the barriers within this category, the isolated working mentality, namely, the forming of silos, is still a norm in the industry (Gelder, 2013), resulting in disruption of relationships and interfaces (Akponeware and Adamu, 2017; Poirier et al., 2017). Moreover, the lack of centrality of the 'BIM manager' and 'BIM coordinator' roles, and their competition with project managers in leading projects can lead to ineffective collaboration (Badi and Diamantidou, 2017; Dossick and Neff, 2009). In essence, much still needs to be learned in managing and 
leading virtual collaborations, with this seen as a barrier to collaboration in BbCNs, in which the main form of collaboration occurs in virtual environments (

\subsubsection{Task barriers}

Task barriers, as shown in Table 5, are the least influential barriers as far as collaboration in BbCNs is concerned.

These have been categorised into two sub-factors: demand and structure. For the sub-factor 'demand', the absence of the demanded information at the right time to complete the task is a significant barrier to successful collaboration (Zanni et al., 2017) and can be attributed to the low quality of communications ( 2017). As for the sub-factor 'structure', complicated tasks, particularly in large BbCNs, can yield diminished collaboration (Mignone et al., 2016).

Table 5. Task-related barriers to collaboration in BbCNs

\begin{tabular}{lll}
\hline Factor & Barrier & Description \\
\hline Structure & Complicated nature of BIM tasks & $\begin{array}{l}\text { Generally, in BIM-enabled projects and due their complex nature and } \\
\text { sheer size, tasks are very complicated, given the involvements and } \\
\text { interactions among multiple stakeholders earlier at the design stage }\end{array}$ \\
\hline Demand & $\begin{array}{l}\text { Absence of the right information at } \\
\text { the right time }\end{array}$ & $\begin{array}{l}\text { Necessary information to complete BIM tasks must be available at the } \\
\text { right time; allocated tasks must be completed at the right time to } \\
\text { provide necessary information for the next party }\end{array}$ \\
\hline
\end{tabular}

Sources: (Mignone et al., 2016; Zanni et al., 2017)

\section{DISCUSSION OF CONCEPTUAL MODEL}

Building on the qualitative findings of previous studies on collaboration in BbCNs, barriers were identified and synthesised, in line with the theoretical lens of the current study, in the form of a conceptual model, as illustrated 
in Figure 4. The conceptual model has implications for scholars, as well as for practitioners, with these described in the next section.

\section{$<<$ INSERT FIGURE 4 HERE $>>$}

Figure 4. Conceptual model of collaboration barriers/factors in BbCNs

\subsection{Contribution to theory and knowledge}

The conceptual model derived from the current study makes two contributions to theory. Firstly, the study

confirms the processual definition of Gray (1985) who conceptualised collaboration as a procedure for problem solving among disparate parties by revealing the importance of process barriers to collaboration (see Figure 3).

This observation is important for understanding collaboration in the context of construction. Secondly, the study contributes specifically to the body of knowledge on BbCNs collaboration. Compared to the now available literature on collaboration in BbCNs, the study's conceptual model advances the related body of knowledge. This provides an extension to the study by Oraee et al. (2017b) in which it was argued that, despite the great deal of scholarship undertaken on the collaboration aspects of BIM, identifying the barriers to collaboration has remained an unexplored area. The study also addresses the calls to incorporate various dimensions of collaboration in BbCNs, despite the dominance of the technology "push" view in the research discourse on collaboration in BIMenabled projects (cf.Liu et al., 2017; Sackey et al., 2015).

At the same time, by presenting a systematic review of the barriers to collaboration in BbCNs, the study makes a significant contribution to the knowledge of how BbCNs collaborate. Previous studies in this field have focused on differing views towards enhancing collaboration in $\mathrm{BbCNs}$; therefore, the need for an overarching context of 
analysis in which all the barriers resulting from such attempts could be incorporated was apparent (Mignone et al., 2016). The conceptual model presented here rewards researchers by providing such a context for the analysis and formulation of future research efforts into BbCNs collaboration. The model strengthens awareness and consideration of the interrelated nature and reciprocal impacts of barriers in affecting BbCNs collaboration. These are all deemed unique features of the current study. In essence, the conceptual model introduces several middlerange theories to be tested in future research on the topic. The conceptual model therefore provides an important foundation for much needed common ground in the focal strand of research on collaboration in BbCNs, with this constituting the key contribution expected of a conceptual model (von Danwitz, 2018).

\subsection{Propositions for project managers}

The knowledge areas defined for managing projects focus on the management of the integration, scope, schedule, quality, resources, communications, risks, procurement and stakeholders on any type of project (PMI, 2017).

Project management within particular sectors, such as construction, requires a tailored approach, particularly when innovative methodologies, such as BIM, are introduced (Ma et al., 2018a). Project managers need specific updates on the scope of work, and on their roles and responsibilities in implementing BIM on their projects, resulting in a new paradigm of project management termed by Ma et al. (2018a) as "BIM-based project management (BPM)". This new paradigm integrates project management requirements into the functional applications of BIM at distinct stages of a building project, to achieve efficient project management in implementing BIM in a project (Ma et al., 2018a). Therefore, BPM is an area directly benefiting from the findings of the current study. The study's conceptual model outlines a set of key practical traits, according to which 
several key recommendations for project managers on BIM-enabled projects can be outlined. The conceptual model can be treated as a central repository of knowledge for project managers in designing teams and maintaining BbCNs collaboration. Overall, the reverse of this model (see Figure 4) could offer a simple tool to translate this new knowledge into checklists or guidelines for controlling and managing BbCNs where collaboration is considered. For example, the managerial implications and practical insights refer to three main propositions:

- Understanding the contribution of both hard and soft factors to team collaboration;

- Mastering BIM-related roles and responsibilities; and

- Developing existing and future project managers.

As aptly highlighted by Liu et al. (2017), many barriers to collaboration in BbCNs come under the umbrella of "soft" factors. These, for the most part, refer to organisational challenges that limit collaboration. These issues are currently addressed through "hard" factors, mostly, technology. However, the systematic use of virtual teamwork principles to adjust organisational settings and structures is an efficient measure for dealing with soft factor problems, in need of immediate attention by project managers (cf.Mignone et al., 2016). To this end, project managers should develop more soft competences when organising such virtual teams.

Further attention is needed in defining BIM roles and responsibilities, and to avoid the confusion and competition between new roles (e.g. BIM manager) and traditional roles, particularly that of project managers. One efficient approach would be to train project managers in BIM technology, thus converting project managers into BIM managers (Akintola et al., 2017). According to Akintola et al. (2017), specialist BIM roles will stay relevant as 
long as the industry is still learning about the technology and, in the future, these roles and responsibilities will be incorporated by project managers (

Notwithstanding attempts to integrate collaboration and multidisciplinary teamwork into BIM education in tertiary education (Becerik-Gerber et al., 2012), this training regime is still in its infancy and, therefore, it is incumbent upon educators to treat collaboration skills as a central element of their BIM-related curricula. In addition, extending collaboration education to all programs pertinent to BIM roles and responsibilities is another avenue to pursue (Zhang et al., 2018). By incorporating BbCNs thinking into curricula, future team members can develop skills in areas not previously covered nor recognised as part of project management education.

Apart from practical implications for project managers, the study findings have practical implications for other project stakeholders, such as software vendors and developers. Despite the advancements and emergence of a wide range of collaboration tools, new tools still need to be designed (Comiskey et al., 2017). These tools must be simpler, more secure platforms in which data ownership and interoperability concerns have been alleviated, and the requirements of an efficient common data environment (CDE) have been satisfied (see Table 1).

\section{CONCLUSION}

This study contributes to the field of collaboration in BbCNs and its impact on project management in several ways. Firstly, the study extracts hitherto-identified barriers to BbCNs collaboration from the available discourse of BIM research, an area in need of immediate attention, where no systematic focus has been dedicated to investigating the barriers to $\mathrm{BbCNs}$ collaboration. The ensuing conceptual model provides a stepping-stone and a theoretical point of departure for future investigators in addressing the issues of collaboration in BbCNs, with this 
being the major contribution of the study. Secondly, the study, in targeting the practice world, provides an efficient tool for project managers on BIM-enabled projects to plan their BbCNs establishment: team arrangements, training needs and managing change, to ensure that barriers to collaboration in their teams have been addressed. From this perspective, the study is unique in providing a comprehensive list of barriers extracted from reliable sources, rather than referring to personal views or anecdotal accounts.

Notwithstanding the study's contributions, the following limitations need to be considered when referring to the study's findings. The model is conceptual in nature and, thus, it requires validation through exposure to real-life data. Therefore, project managers should apply the findings to their projects with caution. Furthermore, collaboration within the boundaries of $\mathrm{BbCNs}$ is targeted by the model; therefore, the findings might not be directly pertinent to the entire supply chain of BIM-enabled projects.

The above limitations, on the other hand, provide areas ripe for research. Validation of the model in the face of empirical data, in various contexts, countries and different types of projects is a new research area created as a result of the current study's findings. Complementary research studies could extend these findings through defining models that capture the interacting and interrelated associations between the identified barriers in the form of causal loop diagrams (CLDs) and networks of barriers. Analysis of such models through exposure to empirical data with techniques such as social network analysis (SNA) is needed to define the root causes of barriers. Future studies also will have the opportunity to build on the current study by delving into the nature of each individual barrier or category of barriers identified. Finding remedial solutions for these barriers is also another fertile ground for research, introduced by the current study's findings. 


\section{REFERENCES}

Abdirad, H., Dossick, C.S., 2016. BIM Curriculum Design in Architecture, Engineering, and Construction Education: A Systematic Review. Journal of Information Technology in Construction, 21, 250-271.

Abrishami, S., Goulding, J.S., Pour-Rahimian, F., Ganah, A., 2014. Integration of BIM and generative design to exploit AEC conceptual design innovation, Journal of Information Technology in Construction. Journal of Information Technology in Construction, 19, 350-359.

Abuelmaatti, A., Ahmed, V., 2014. Collaborative technologies for small and medium-sized architecture, engineering and construction enterprises: implementation survey. ITCON special issue: emerging digital technologies and innovations.

ACIF, APCC, 2015. Building and Construction Procurement Guide: Project Team Integration and Building Information Modelling. Australian Construction Industry Forum and Australasian Procurement and Construction Council, Canberra, Australia.

ACIF, APCC, 2017. BIM Knowledge and Skills Framework: An Introduction. The Australian Construction Industry Forum (ACIF) and Australasian Procurement and Construction Council (APCC), Canberra, ACT, Australia.

Akintola, A., Venkatachalam, S., Root, D., 2017. New BIM Roles’ Legitimacy and Changing Power Dynamics on BIM-Enabled Projects. Journal of Construction Engineering and Management, 143.

Akponeware, A.O., Adamu, Z.A., 2017. Clash Detection or Clash Avoidance? An Investigation into Coordination Problems in 3D BIM. Buildings, 7, 75 .

Alreshidi, E., Mourshed, M., Rezgui, Y., 2016a. Cloud-based BIM governance platform requirements and specifications: Software engineering approach using BPMN and UML. Journal of Computing in Civil Engineering, 30.

Alreshidi, E., Mourshed, M., Rezgui, Y., 2016b. Requirements for cloud-based BIM governance solutions to facilitate team collaboration in construction projects. Requirements Engineering, 1-31.

Alreshidi, E., Mourshed, M., Rezgui, Y., 2017. Factors for effective BIM governance. Journal of Building Engineering, 10, 89-101.

Alwash, A., Love, P.E.D., Olatunji, O., 2017. Impact and Remedy of Legal Uncertainties in Building Information Modeling. Journal of Legal Affairs and Dispute Resolution in Engineering and Construction, 9, 04517005.

Amann, J., Borrmann, A., 2016. Embedding Procedural Knowledge into Building Information Models: The IFC Procedural Language and Its Application for Flexible Transition Curve Representation. Journal of Computing in Civil Engineering, 30 , C4016006.

Arayici, Y., Coates, P., Koskela, L., Kagioglou, M., Usher, C., O'Reilly, K., 2011. Technology adoption in the BIM implementation for lean architectural practice. Automation in Construction, 20, 189-195.

Arayici, Y., Fernando, T., Munoz, V., Bassanino, M., 2018. Interoperability specification development for integrated BIM use in performance based design. Automation in Construction, 85, 167-181. 
Ashcraft, H.W., 2008. Building information modeling: A framework for collaboration. Constr. Law., 28, 5-18.

Baddeley, M., Chang, D.C.-Y., 2015. Collaborative Building Information Modelling (BIM): Insights from Behavioural Economics and Incentive Theory. Royal Institution of Chartered Surveyors (RICS), London, UK.

Badi, S., Diamantidou, D., 2017. A social network perspective of building information modelling in Greek construction projects. Architectural Engineering and Design Management, 1-17.

Bassanino, M., Fernando, T., Wu, K.-C., 2014. Can virtual workspaces enhance team communication and collaboration in design review meetings? Architectural Engineering and Design Management, 10, 200-217.

Bazeley, P., 2013. Qualitative data analysis : practical strategies. SAGE, Thousand Oaks, Calif.

Beach, T., Petri, I., Rezgui, Y., Rana, O., 2017. Management of Collaborative BIM Data by Federating Distributed BIM Models. Journal of Computing in Civil Engineering, 04017009.

Becerik-Gerber, A.M.A., B., Ku, K., Jazizadeh, F., 2012. BIM-Enabled Virtual and Collaborative Construction Engineering and Management. Journal of professional issues in engineering education and practice, 138, 234-245.

Becerik-Gerber, B., Gerber, D.J., Ku, K., 2011. The pace of technological innovation in architecture, engineering, and construction education: integrating recent trends into the curricula. Journal of Information Technology in Construction, 16, 411-432.

Beesley, C., 2013. BIM for Govies ${ }^{\mathrm{TM}}$. DLT Solutions, LLC, Herndon, VA.

Boton, C., Kubicki, S., Halin, G., 2013. Designing adapted visualization for collaborative 4D applications. Automation in Construction, $36,152-167$.

Bouchlaghem, D., Shang, H., Whyte, J., Ganah, A., 2005. Visualisation in architecture, engineering and construction (AEC). Automation in Construction, 14, 287-295.

Bozoglu, J., 2016. Collaboration and coordination learning modules for BIM education. Journal of Information Technology in Construction, 21, 152-163.

Brodie, M., 2010. Building information modelling: the UK legal context. International Journal of Law in the Built Environment, 2 , 246-259.

Bryde, D., Broquetas, M., Volm, J.M., 2013. The project benefits of Building Information Modelling (BIM). International Journal of Project Management, 31, 971-980.

Caniëls, M.C.J., Chiocchio, F., van Loon, N.P.A.A., 2019. Collaboration in project teams: The role of mastery and performance climates. International Journal of Project Management, 37, 1-13.

Cao, D., Li, H., Wang, G., Huang, T., 2017a. Identifying and contextualising the motivations for BIM implementation in construction projects: An empirical study in China. International Journal of Project Management, 35, 658-669. 
Cao, D., Li, H., Wang, G., Luo, X., Tan, D., 2018. Relationship Network Structure and Organizational Competitiveness: Evidence from BIM Implementation Practices in the Construction Industry. Journal of Management in Engineering, 34, 04018005.

Cao, D., Li, H., Wang, G., Luo, X., Yang, X., Tan, D., 2017b. Dynamics of project-based collaborative networks for BIM implementation: Analysis based on stochastic actor-oriented models. Journal of Management in Engineering, 33, 04016055.

Cao, D., Li, H., Wang, G., Zhang, W., 2016. Linking the motivations and practices of design organizations to implement building information modeling in construction projects: Empirical study in China. Journal of Management in Engineering, 32, 04016013.

Cao, D., Wang, G., Li, H., Skitmore, M., Huang, T., Zhang, W., 2015. Practices and effectiveness of building information modelling in construction projects in China. Automation in Construction, 49, 113-122.

Charalambous, G., Demian, P., Yeomans, S., Thorpe, T., 2017. Impact of collaboration tools and shaping the future of data exchange - A model for BIM communication waste, in: Perera, S., Ingirige, B., Ruikar, K., Obonyo, E. (Eds.), Advances in Construction ICT and e-Business. CRC Press, London, UK.

Chen, H.-M., Hou, C.-C., 2014. Asynchronous online collaboration in BIM generation using hybrid client-server and P2P network. Automation in Construction, 45, 72-85.

Chen, S.-M., Griffis, F.H., Chen, P.-H., Chang, L.-M., 2013. A framework for an automated and integrated project scheduling and management system. Automation in Construction, 35, 89-110.

Ciribini, A.L.C., Mastrolembo Ventura, S., Paneroni, M., 2016. Implementation of an interoperable process to optimise design and construction phases of a residential building: A BIM Pilot Project. Automation in Construction.

Comiskey, D., McKane, M., Jaffrey, A., Wilson, P., Mordue, S., 2017. An analysis of data sharing platforms in multidisciplinary education. Architectural Engineering and Design Management, 13, 244-261.

CPNI, 2015. Specification for security-minded building information modelling, digital built environments and smart asset management Centre for the Protection of National Infrastructure (CPNI), The British Standards Institution.

Crotty, M., 1998. The foundations of social research: Meaning and perspective in the research process. Sage.

D'Amour, D., Ferrada-Videla, M., San Martin Rodriguez, L., Beaulieu, M.-D., 2005. The conceptual basis for interprofessional collaboration: core concepts and theoretical frameworks. Journal of interprofessional care, 19, 116-131.

Dossick, C., Neff, G., 2009. Organizational Divisions in BIM-Enabled Commercial Construction. Journal of Construction Engineering and Management, 136, 459-467.

Dossick, C.S., Neff, G., 2010. Organizational Divisions in BIM-Enabled Commercial Construction. Journal of Construction Engineering and Management, 136, 459-467.

Dossick, C.S., Neff, G., 2011. Messy talk and clean technology: communication, problem-solving and collaboration using Building Information Modelling. The Engineering Project Organization Journal, 1, 83-93. 
Du, J., Shi, Y., Zou, Z., Zhao, D., 2017. CoVR: Cloud-Based Multiuser Virtual Reality Headset System for Project Communication of Remote Users. Journal of Construction Engineering and Management, 144, 04017109.

Eastman, C., Teicholz, P., Sacks, R., Liston, K., 2008. BIM Handbook: A Guide to Building Information Modeling for Owners, Managers, Designers, Engineers, and Contractors, Second ed. John Wiley \& Sons Inc., Hoboken, New Jersey, USA.

El-Diraby, T., Krijnen, T., Papagelis, M., 2017. BIM-based collaborative design and socio-technical analytics of green buildings. Automation in Construction, 82, 59-74.

Emmitt, S., Ruikar, K., 2013. Collaborative design management. Routledge, London

Ey, W., Zuo, J., Han, S., 2014. Barriers and challenges of collaborative procurements: An exploratory study. International Journal of Construction Management, 14, 148-155.

Fernando, T., Wu, K.-C., Bassanino, M., 2013. Designing a novel virtual collaborative environment to support collaboration in design review meetings. Journal of Information Technology in Construction, 18, 372-396.

Franz, B., Leicht, R., Molenaar, K., Messner, J., 2016. Impact of Team Integration and Group Cohesion on Project Delivery Performance. Journal of Construction Engineering and Management, 0, 04016088.

Fu, C., Aouad, G., Lee, A., Mashall-Ponting, A., Wu, S., 2006. IFC model viewer to support nD model application. Automation in Construction, $15,178-185$.

Fulford, R., Standing, C., 2014. Construction industry productivity and the potential for collaborative practice. International Journal of Project Management, 32, 315-326.

Gann, D.M., Salter, A.J., 2000. Innovation in project-based, service-enhanced firms: the construction of complex products and systems. Research policy, 29, 955-972.

Gelder, J., 2013. Removing barriers to collaboration in the built environment National Building Specification (NBS UK).

Goulding, J.S., Pour Rahimian Leilabadi, F., Wang, X., 2014. Virtual reality-based cloud BIM platform for integrated AEC projects. Journal of Information Technology in Construction, 19, 308-325.

Gray, B., 1985. Conditions facilitating interorganizational collaboration. Human relations, 38, 911-936.

Greene, J.C., 2008. Is mixed methods social inquiry a distinctive methodology? Journal of mixed methods research, 2, 7-22.

Greenwood, D., Wu, S., 2012. Establishing the association between collaborative working and construction project performance based on client and contractor perceptions. Construction Management and Economics, 30, 299-308.

Grilo, A., Jardim-Goncalves, R., 2010. Value proposition on interoperability of BIM and collaborative working environments. Automation in Construction, 19, 522-530. 
Grilo, A., Jardim-Goncalves, R., 2013. Cloud-Marketplaces: Distributed e-procurement for the AEC sector. Advanced Engineering Informatics, 27, 160-172.

Grilo, A., Zutshi, A., Jardim-Goncalves, R., Steiger-Garcao, A., 2013. Construction collaborative networks: the case study of a building information modelling-based office building project. International Journal of Computer Integrated Manufacturing, 26, 152-165.

Gu, N., London, K., 2010. Understanding and facilitating BIM adoption in the AEC industry. Automation in Construction, 19, 988999.

Hassan Ibrahim, N., 2013. Reviewing the evidence: use of digital collaboration technologies in major building and infrastructure projects. Journal of Information Technology in Construction.

He, Q., Wang, G., Luo, L., Shi, Q., Xie, J., Meng, X., 2017. Mapping the managerial areas of Building Information Modeling (BIM) using scientometric analysis. International Journal of Project Management, 35, 670-685.

Hoekstra, J., 2003. Big buzz for BIM: is the latest approach to A/E/C software a revolutionary one or just repackaged technology at a higher price? (Tech). Architecture, 92, 79-81.

Hooper, M., 2015. BIM standardisation efforts-the case of Sweden. Journal of Information Technology in Construction, 20, 332346.

Hosseini, M.R., Banihashemi, S., Chileshe, N., Namzadi, M.O., Udaeja, C., Rameezdeen, R., McCuen, T., 2016. BIM adoption within Australian Small and Medium-sized Enterprises (SMEs): an innovation diffusion model. Construction Economics and Building, 16, $71-86$.

Hosseini, M.R., Martek, I., Papadonikolaki, E., Sheikhkhoshkar, M., Banihashemi, S., Arashpour, M., 2018. Viability of the BIM Manager Enduring as a Distinct Role: Association Rule Mining of Job Advertisements. Journal of Construction Engineering and Management, 144, 04018085.

Hosseini, M.R., Zavadskas, E.K., Xia, B., Chileshe, N., Mills, A., 2017. Communications in Hybrid Arrangements: Case of Australian Construction Project Teams. Engineering Economics, 28, 290-300.

Howard, R., Restrepo, L., Chang, C.-Y., 2017. Addressing individual perceptions: An application of the unified theory of acceptance and use of technology to building information modelling. International Journal of Project Management, 35, 107-120.

Hu, Z.-Z., Zhang, X.-Y., Wang, H.-W., Kassem, M., 2016. Improving interoperability between architectural and structural design models: An industry foundation classes-based approach with web-based tools. Automation in Construction, 66, 29-42.

Hu, Z., Zhang, J., 2011. BIM- and 4D-based integrated solution of analysis and management for conflicts and structural safety problems during construction: 2. Development and site trials. Automation in Construction, 20, 167-180.

Hughes, D., Williams, T., Ren, Z., 2012. Differing perspectives on collaboration in construction. Construction Innovation, 12, 355368. 
Isikdag, U., 2012. Design patterns for BIM-based service-oriented architectures. Automation in Construction, 25, 59-71.

Isikdag, U., Underwood, J., 2010. Two design patterns for facilitating Building Information Model-based synchronous collaboration. Automation in Construction, 19, 544-553.

Jiao, Y., Wang, Y., Zhang, S., Li, Y., Yang, B., Yuan, L., 2013. A cloud approach to unified lifecycle data management in architecture, engineering, construction and facilities management: Integrating BIMs and SNS. Advanced Engineering Informatics, 27, 173188.

Kalantari, S., Shepley, M.M., Rybkowski, Z.K., Bryant, J., 2017. Designing for operational efficiency: facility managers’ perspectives on how their knowledge can be better incorporated during design. Architectural Engineering and Design Management, 13, $457-478$.

Kalay, Y.E., 2001. Enhancing multi-disciplinary collaboration through semantically rich representation. Automation in Construction, 10, 741-755.

Kent, D.C., Becerik-Gerber, B., 2010. Understanding Construction Industry Experience and Attitudes toward Integrated Project Delivery. Journal of Construction Engineering and Management, 136, 815-825.

Kihong Ku, Mahabaleshwarkar, P.S., 2011. Building interactive modeling for construction education in virtual worlds. Journal of Information Technology in Construction, Vol. 16, pg. 189-208.

Kim, M., Ji, S., Jun, H., 2017. BIM-based File Synchronization and Permission Management System for Architectural Design Collaboration. Journal of Asian Architecture and Building Engineering, 16, 511-518.

Kokkonen, A., Alin, P., 2016. Practitioners deconstructing and reconstructing practices when responding to the implementation of BIM. Construction Management and Economics, 34, 578-591.

Ku K, Pollalis S, Fischer M, D, S., 2008. 3D model-based collaboration in design development and construction of complex shaped buildings. Journal of Information Technology in Construction, Vol. 13, pg. 258-285.

Ku, K., Pollalis, S., 2009. Contractual standards for enhanced geometry control in model-based collaboration. Journal of Information Technology in Construction.

Kuiper, I., Holzer, D., 2013. Rethinking the contractual context for Building Information Modelling (BIM) in the Australian built environment industry. Construction Economics and Building, 13, 1-17.

Lee, Y.-C., Eastman, C.M., Lee, J.-K., 2015. Validations for ensuring the interoperability of data exchange of a building information model. Automation in Construction, 58, 176-195.

Lewins, A., Silver, C., 2007. Using software in qualitative research. SAGE Publications, London, England. 
Liao, L., Teo, E.A.L., Low, S.P., 2017. A project management framework for enhanced productivity performance using building information modelling. Construction Economics and Building, 17, 1-26.

Liu, H., Al-Hussein, M., Lu, M., 2015. BIM-based integrated approach for detailed construction scheduling under resource constraints. Automation in Construction, 53, 29-43.

Liu, Q., Gao, T., 2017. The Information Requirements for Transportation Industry's Facilities Management Based on BIM. The Open Construction and Building Technology Journal, 11.

Liu, Y., van Nederveen, S., Hertogh, M., 2017. Understanding effects of BIM on collaborative design and construction: An empirical study in China. International Journal of Project Management, 35, 686-698.

London, K., Singh, V., 2012. Integrated construction supply chain design and delivery solutions. Architectural Engineering and Design Management, 9, 135-157.

Ma, X., Xiong, F., Olawumi, T.O., Dong, N., Chan, A.P.C., 2018a. Conceptual Framework and Roadmap Approach for Integrating BIM into Lifecycle Project Management. Journal of Management in Engineering, 34, 05018011.

Ma, Z., Ma, J., 2017. Formulating the application functional requirements of a BIM-based collaboration platform to support IPD projects. KSCE Journal of Civil Engineering, 1-16.

Ma, Z., Zhang, D., Li, J., 2018b. A dedicated collaboration platform for Integrated Project Delivery. Automation in Construction, $86,199-209$.

Manderson, A., Jefferies, M., Brewer, G., 2015. Building information modelling and standardised construction contracts: a content analysis of the GC21 contract. Construction Economics and Building, 15, 72-84.

Manderson, A.D., Jefferies, M.C., Brewer, G.J., 2017. An Analysis of the Intergration of Building Information Modelling (BIM) in Standard Construction Contracts in: Peng, W., Haijiang, L., Xiangyu, W. (Eds.), Integrated Building Information Modelling. Bentham Science Publishers, Sharjah, UAE.

Matthews, J., Love, P.E., Mewburn, J., Stobaus, C., Ramanayaka, C., 2018. Building information modelling in construction: insights from collaboration and change management perspectives. Production Planning \& Control, 29, 202-216.

Merschbrock, C., 2012. Unorchestrated symphony: The case of inter-organizational collaboration in digital construction design. Journal of Information Technology in Construction, 17, 333-350.

Merschbrock, C., Hosseini, M.R., Martek, I., Arashpour, M., Mignone, G., 2018. Collaborative Role of Sociotechnical Components in BIM-Based Construction Networks in Two Hospitals. Journal of Management in Engineering, 34, 05018006.

Merschbrock, C., Munkvold, B.E., 2014. How is Building Information Modeling Influenced by Project Complexity?: A Cross-Case Analysis of e-Collaboration Performance in Building Construction. International Journal of e-Collaboration (IJeC), 10, $20-39$. 
Mignone, G., Hosseini, M.R., Chileshe, N., Arashpour, M., 2016. Enhancing collaboration in BIM-based construction networks through organisational discontinuity theory: a case study of the new Royal Adelaide Hospital. Architectural Engineering and Design Management, 12, 333-352.

Miles, M.B., Huberman, A.M., 1994. Qualitative data analysis: An expanded sourcebook. Sage Publications Inc., Thousant Oaks, CA.

Morris, P.W.G., 2004. Project management in the construction industry, in: Morris, P.W.G., Pinto, J.K. (Eds.), The Wiley guide to managing projects. John Wiley \& Sons, Hoboken, NJ, pp. 1350-1367.

Nikas, A., Poulymenakou, A., Kriaris, P., 2007. Investigating antecedents and drivers affecting the adoption of collaboration technologies in the construction industry. Automation in Construction, 16, 632-641.

Niknam, M., Karshenas, S., 2015. Integrating distributed sources of information for construction cost estimating using Semantic Web and Semantic Web Service technologies. Automation in Construction, 57, 222-238.

Ochieng, E.G., Price, A.D.F., 2010. Managing cross-cultural communication in multicultural construction project teams: The case of Kenya and UK. International Journal of Project Management, 28, 449-460.

Olatunji, O.A., 2011a. Modelling organizations' structural adjustment to BIM adoption: a pilot study on estimating organizations. Journal of Information Technology in Construction, 16, 653-668.

Olatunji, O.A., 2011b. A preliminary review on the legal implications of BIM and model ownership. Journal of Information Technology in Construction, 16, 687-696.

Oraee, M., Hosseini, M.R., Namini, S.B., Merschbrock, C., 2017a. Where the gaps lie: Ten years of research into collaboration on BIM-enabled construction projects. Construction Economics and Building, 17, 121-139.

Oraee, M., Hosseini, M.R., Papadonikolaki, E., Palliyaguru, R., Arashpour, M., 2017b. Collaboration in BIM-based construction networks: A bibliometric-qualitative literature review. International Journal of Project Management, 35, 1288-1301.

Owen, R., Amor, R., Palmer, M., Dickinson, J., Tatum, C.B., Kazi, A.S., Prins, M., Kiviniemi, A., East, B., 2010. Challenges for Integrated Design and Delivery Solutions. Architectural Engineering and Design Management, 6, 232-240.

Papadonikolaki, E., Vrijhoef, R., Wamelink, H., 2016. The interdependences of BIM and supply chain partnering: empirical explorations. Architectural Engineering and Design Management, 12, 476-494.

Paré, G., Trudel, M.-C., Jaana, M., Kitsiou, S., 2015. Synthesizing information systems knowledge: A typology of literature reviews. Information \& Management, 52, 183-199.

Patel, H., Pettitt, M., Wilson, J.R., 2012. Factors of collaborative working: A framework for a collaboration model. Applied Ergonomics, 43, 1-26. 
Pikas, E., Sacks, R., Hazzan, O., 2013a. Building Information Modeling Education for Construction Engineering and Management. II: Procedures and Implementation Case Study. Journal of Construction Engineering and Management, 139, http://dx.doi.org/10.1061/(ASCE)CO.1943-7862.0000765, 05013002.

Pikas, E., Sacks, R., Hazzan, O., 2013b. Building Information Modeling Education for Construction Engineering and Management. II: Procedures and Implementation Case Study. Journal of Construction Engineering and Management, 139, 05013002.

PMI, 2017. A guide to the Project Management Body of Knowledge (PMBOK Guide), 6 ed. Project Management Institute Standards Committee, Newtown Square, Pennsylvania.

Poirier, E., Forgues, D., Staub-French, S., 2016. Collaboration through innovation: implications for expertise in the AEC sector. Construction Management and Economics, 1-21.

Poirier, E.A., Forgues, D., Staub-French, S., 2017. Understanding the impact of BIM on collaboration: a Canadian case study. Building Research \& Information, 1-15.

Rafiq, M., Rustell, M., 2013. Building Information Modeling Steered by Evolutionary Computing. Journal of Computing in Civil Engineering, 28, 05014003.

Rezgui, Y., Beach, T., Rana, O., 2013. A Governance Approach for BIM Management across Lifecycle and Supply Chains Using Mixed-Modes of Information Delivery. Journal of Civil Engineering and Management, 19, 239-258.

Sackey, E., Tuuli, M., Dainty, A., 2015. Sociotechnical systems approach to BIM implementation in a multidisciplinary construction context. Journal of Management in Engineering, 31.

Sacks, R., Pikas, E., 2013. Building Information Modeling Education for Construction Engineering and Management. I: Industry Requirements, State of the Art, and Gap Analysis. Journal of Construction Engineering and Management, 139, 04013016.

Sacks, R.a., Barak, R., Geva, G., Korb, S., 2018. Building lean, building BIM : improving construction the Tidhar way. New York, NY : Routledge, 2018.

Saldanā, J., 2009. The Coding Manual for Qualitative Researchers. SAGE Publications Ltd, London, UK.

Santos, R., Costa, A.A., Grilo, A., 2017. Bibliometric analysis and review of Building Information Modelling literature published between 2005 and 2015. Automation in Construction, 80, 118-136.

Shafiq, M.T., Matthews, J., Lockley, S., 2013. A study of BIM collaboration requirements and available features in existing model collaboration systems. Journal of Information Technology in Construction, 18, 148-161.

Shen, W., Hao, Q., Mak, H., Neelamkavil, J., Xie, H., Dickinson, J., Thomas, R., Pardasani, A., Xue, H., 2010. Systems integration and collaboration in architecture, engineering, construction, and facilities management: A review. Advanced Engineering Informatics, 24, 196-207. 
Shields, P.M., Tajalli, H., 2006. Intermediate Theory: The Missing Link in Successful Student Scholarship. Journal of Public Affairs Education, 12, 313-334.

Shin, T.-S., 2017. Building information modeling (BIM) collaboration from the structural engineering perspective. International Journal of Steel Structures, 17, 205-214.

Sidawi, B., Hamza, N., 2012. Intelligent knowledge-based repository to support informed design decision making. ITCON special issue: CAAD and innovation. pg, 308-318.

Singh, V., Gu, N., Wang, X., 2011. A theoretical framework of a BIM-based multi-disciplinary collaboration platform. Automation in Construction, 20, 134-144.

Solnosky, R., Parfitt, M.K., Holland, R., 2014. Delivery methods for a multi-disciplinary architectural engineering capstone design course. Architectural Engineering and Design Management, 11, 305-324.

Solnosky, R.L., 2016. Integrated Structural Processes on Innovative Multidisciplinary Projects Supported by Building Information Modeling. Journal of Architectural Engineering, 23, 05016004.

Stirton, L., Tree, J., 2015. IPD and BIM: A new dimension to collaboratio. Mills Oakley.

Succar, B., 2009. Building information modelling framework: A research and delivery foundation for industry stakeholders. Automation in Construction, 18, 357-375.

Taylor, J.E., 2007. Antecedents of Successful Three-Dimensional Computer-Aided Design Implementation in Design and Construction Networks. Journal of Construction Engineering and Management, 133, 993-1002.

Tingting, M., Qiankun, W., Yaping, X., Mi, Y., 2017. Rent-seeking behavior of BIM- and IPD-based construction project in China. Engineering, Construction and Architectural Management, 24, 514-536.

Tranfield, D., Denyer, D., Smart, P., 2003. Towards a Methodology for Developing Evidence-Informed Management Knowledge by Means of Systematic Review. British Journal of Management, 14, 207-222.

Turk, Ž., 2016. Ten questions concerning building information modelling. Building and Environment, 107, $274-284$.

Van Gassel, F., Láscaris-Comneno, T., Maas, G., 2014. The conditions for successful automated collaboration in construction. Automation in Construction, 39, 85-92.

von Danwitz, S., 2018. Managing inter-firm projects: A systematic review and directions for future research. International Journal of Project Management.

Walker, D.H., Davis, P.R., Stevenson, A., 2017. Coping with uncertainty and ambiguity through team collaboration in infrastructure projects. International Journal of Project Management, 35, 180-190. 
Wallace Imoudu, E., Uche Godwin, A., Kherun Nita, A., 2014. Preliminary building information modelling adoption model in Malaysia. Construction Innovation, 14, 408-432.

Wei, Z., David, H., Panagiotis, G., Joseph, H.M.T., 2014. User-centred design for collaborative 4D modelling. Construction Innovation, 14, 493-517.

Whetten, D.A., 1989. What constitutes a theoretical contribution? Academy of Management Review, 14, 490-495.

Williams, A.P., 2016. The Development of Collaboration Theory Typologies and Systems Approaches, in: Morris, J.C., MillerStevens, K. (Eds.), Advancing Collaboration Theory : Models, Typologies, and Evidence. Routledge, New York, NY.

Wu, W., Issa, R.R., 2013. BIM education and recruiting: Survey-based comparative analysis of issues, perceptions, and collaboration opportunities. Journal of professional issues in engineering education and practice, 140, 04013014.

Yalcinkaya, M., Singh, V., 2015. Patterns and trends in Building Information Modeling (BIM) research: A Latent Semantic Analysis. Automation in Construction, 59, 68-80.

Zanni, M.A., Soetanto, R., Ruikar, K., 2017. Towards a BIM-enabled sustainable building design process: roles, responsibilities, and requirements. Architectural Engineering and Design Management, 13, 101-129.

Zhang, J., Liu, Q., Hu, Z., Lin, J., Yu, F., 2017a. A multi-server information-sharing environment for cross-party collaboration on a private cloud. Automation in Construction, 81, 180-195.

Zhang, J., Wu, W., Li, H., 2018. Enhancing Building Information Modeling Competency among Civil Engineering and Management Students with Team-Based Learning. Journal of professional issues in engineering education and practice, $144,05018001$.

Zhang, L., Ashuri, B., 2018. BIM log mining: Discovering social networks. Automation in Construction, 91, 31-43.

Zhang, S., Pan, F., Wang, C., Sun, Y., Wang, H., 2017b. BIM-Based Collaboration Platform for the Management of EPC Projects in Hydropower Engineering. Journal of Construction Engineering and Management, 143, 04017087.

Zhao, D., McCoy, A.P., Bulbul, T., Fiori, C., Nikkhoo, P., 2015. Building Collaborative Construction Skills through BIMintegrated Learning Environment. International Journal of Construction Education and Research, 11, 97-120.

Zhao, X., Feng, Y., Pienaar, J., O’Brien, D., 2017. Modelling paths of risks associated with BIM implementation in architectural, engineering and construction projects. Architectural Science Review, 60, 472-482. 


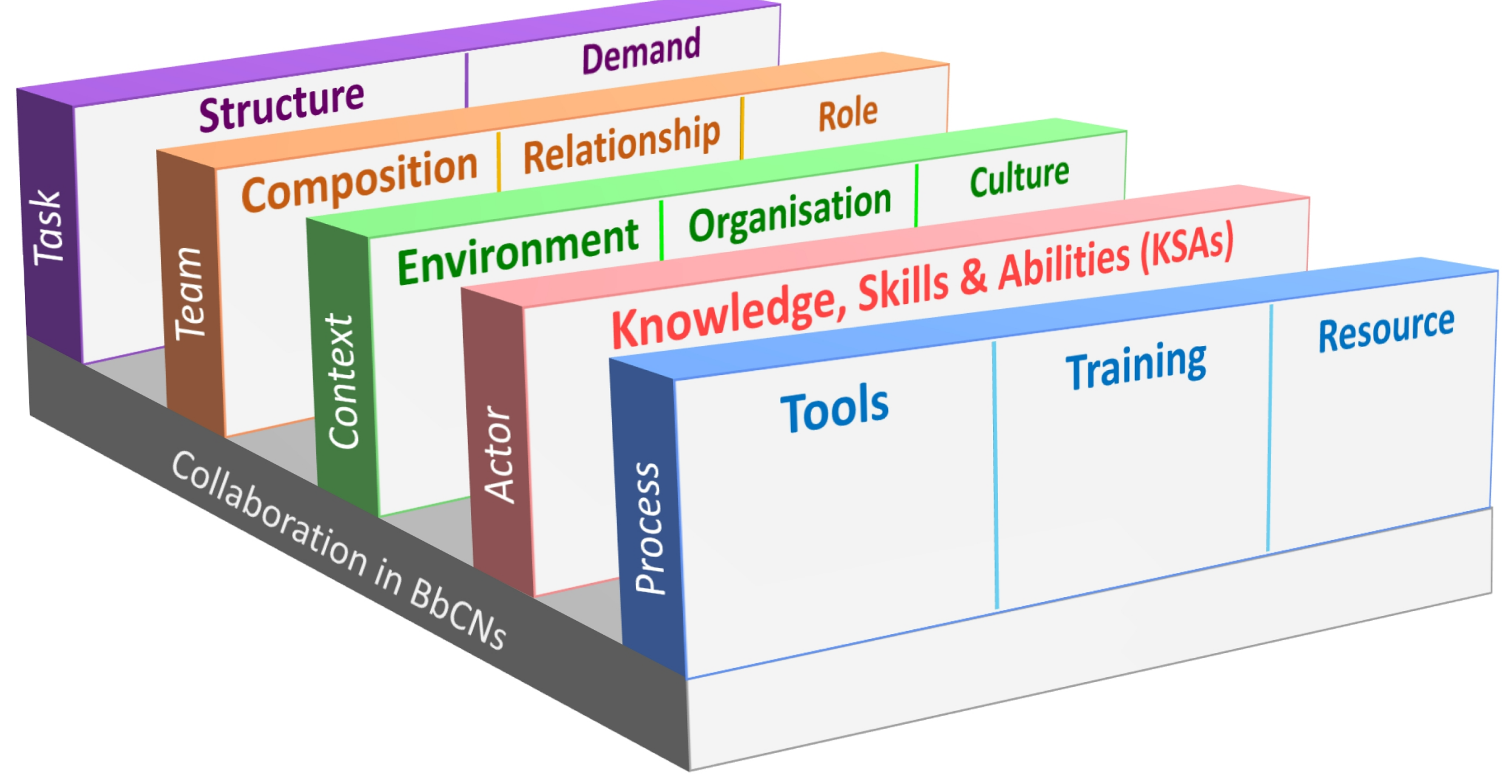




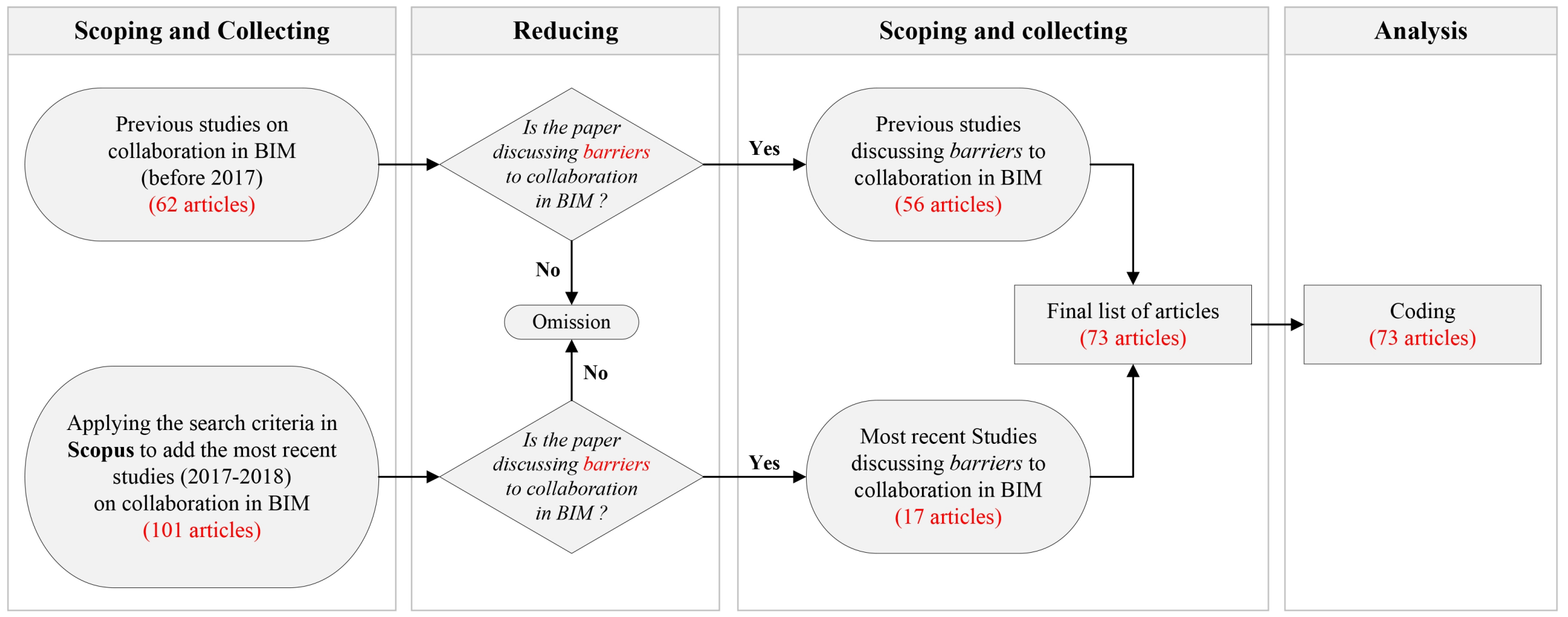




\section{Number of identified barriers}

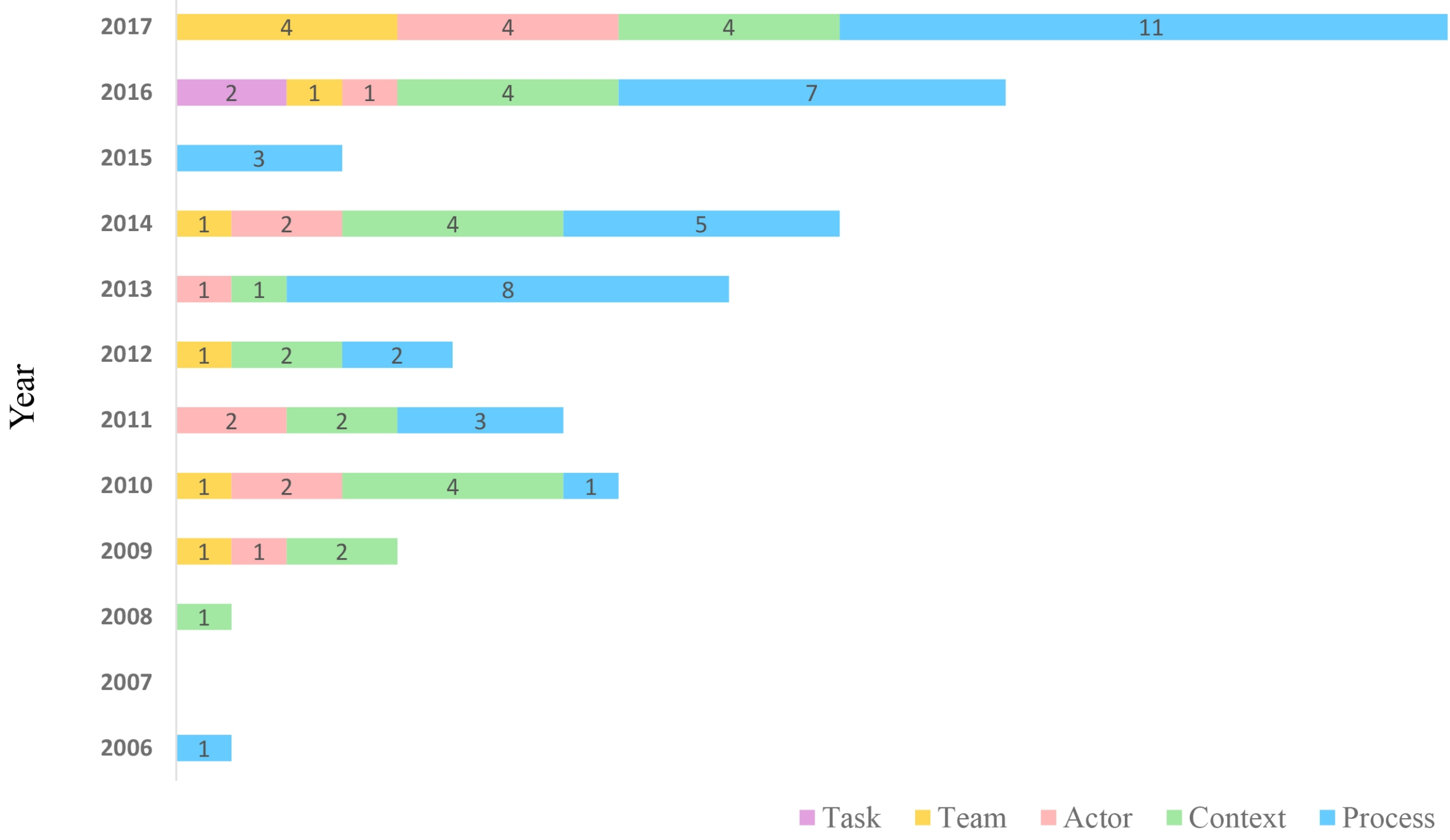




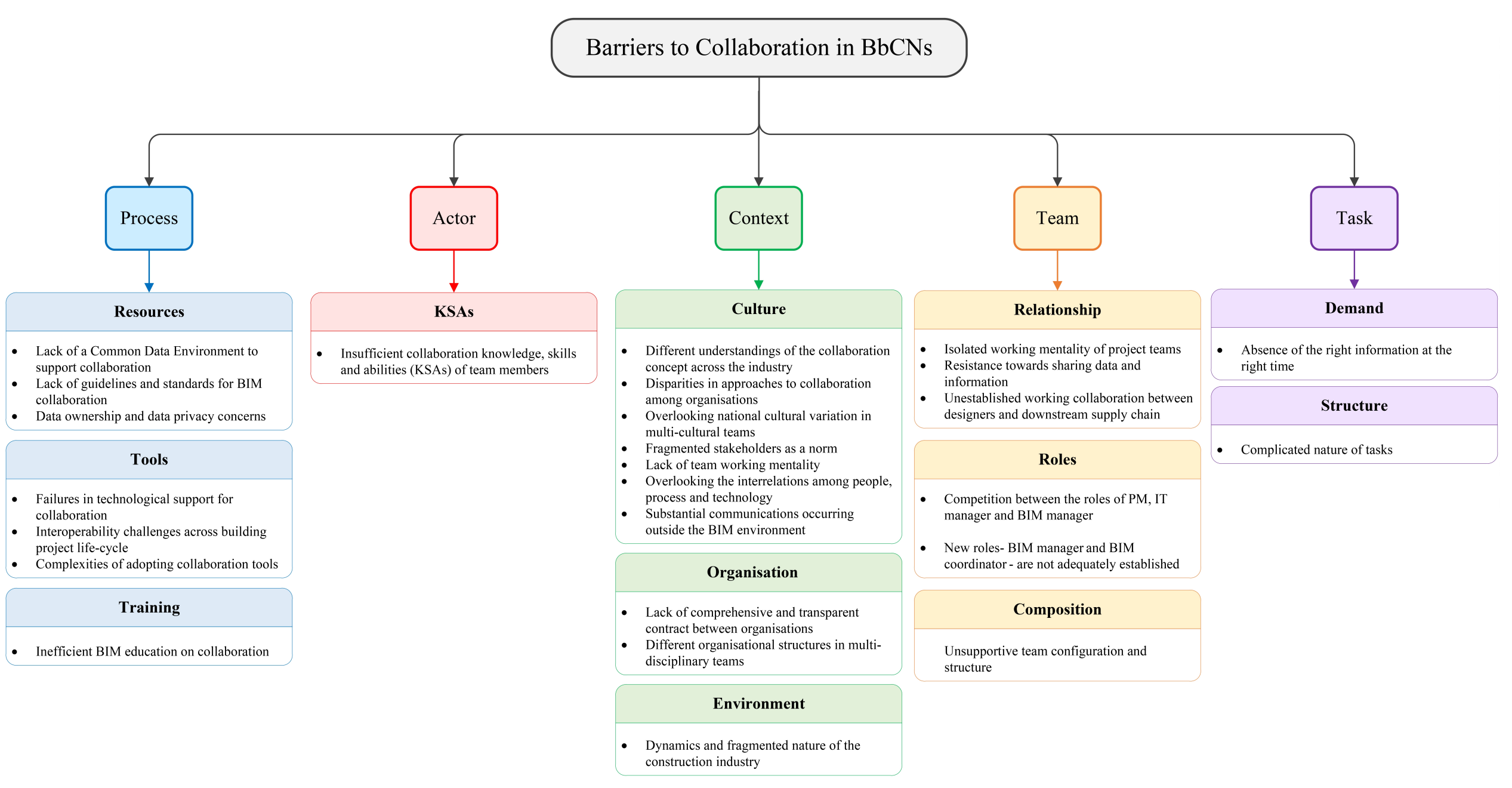




\section{Appendix}

Search term and criteria utilised this research to search for relevant studies on

\section{'Scopus'}

[1] ( TITLE-ABS-KEY ( "building information modelling" OR "building information modeling" ) AND

[2] DOCTYPE ( ar OR re ) AND SUBJAREA (mult OR ceng OR chem OR comp OR eart OR ener O $\mathrm{R}$ engi OR envi OR mate OR math OR phys OR mult OR arts OR busi OR deci OR econ OR ps yc OR soci) AND PUBYEAR > 2004 ) AND ( collaboration) 